\title{
Market Power, Permit Allocation and Efficiency in Emission Permit Markets
}

\author{
Beat Hintermann
}

Accepted: 11 November 2010 / Published online: 30 November 2010

(C) Springer Science+Business Media B.V. 2010

\begin{abstract}
Market power in permit markets has been examined in some detail following the seminal work of Hahn (Q J Econ 99(4):753-765, 1984), but the effect of free allocation on price manipulation with market power in both product and permit market has not been fully addressed. I show that in this case, the threshold of free allocation above which a dominant firm will set the permit price above its marginal abatement costs is below its optimal emissions in a competitive market, and that overall efficiency cannot be achieved by means of permit allocation alone. In addition to being of general economic interest, this issue is relevant in the context of the EU ETS. I find that the largest German, UK and Nordpool power generators received free allowances in excess of the derived threshold. Conditional on having price-setting power in both the electricity and permit markets, these firms would have found it profitable to manipulate the permit price upwards despite being net permit buyers.
\end{abstract}

Keywords $\mathrm{CO}_{2} \cdot$ Cost pass-through $\cdot$ Emission permit markets $\cdot$ EU ETS ·

Market power $\cdot$ Permit allocation

JEL Classification $\quad$ D42-43 $\cdot$ L11-13 $\cdot$ L94 $\cdot$ Q52-54

\section{Introduction}

During the first 18 months of the European Union Emissions Trading Scheme (EU ETS), the allowance price per ton of $\mathrm{CO}_{2}$ was far in excess of pre-market expectations. The price fell dramatically in April 2006 when the first round of emissions verifications implied that the new market was in fact over-allocated with permits, but it did not reach zero until mid 2007. A series of empirical studies (Mansanet-Bataller et al. 2007; Rickels et al. 2007; Alberola and Chevallier 2008; Bunn and Fezzi 2008; Hintermann 2009, 2010) have attempted to explain

B. Hintermann $(\varangle)$

Faculty of Business and Economics,

University of Basel, Peter Merian-Weg 6, 4002 Basel, Switzerland

e-mail: b.hintermann@unibas.ch 
the price path by market fundamentals such as fuel prices and weather variables, but only with limited success. Market fundamentals appear to be able to explain a part of the allowance price variation in the period after the April price crash, but only to a very small extent before the price adjustment. Moreover, none of these studies is able to explain the price level during the first phase, which in hindsight was clearly too high, considering the fact that the number of allowances exceeded emissions in every year of the first phase. An inflated permit price destroys the most powerful argument in favor of instituting pollution permit markets, which is to achieve a given emissions target at least cost.

In this paper I examine whether price manipulation within the EU electricity sector could have inflated the permit price beyond the efficient level, defined as the level where it equals marginal abatement costs of all firms in the market. I set up a model where a dominant firm has market power in both the product and the permit market and explicitly account for crossmarket links. By solving the model I derive the permit allocation threshold above which the dominant firm will exercise its market power to increase the permit price and maximize thus overall profits in both markets. The threshold is below the neutral allocation threshold proposed by Hahn (1984) under the assumption of market power in the permit market only. This is the core result of my paper and means that a dominant firm could find it profitable to manipulate the permit price upwards even if it is a net permit buyer, provided it receives a sufficiently large permit allocation and that it can pass on its carbon costs to consumers. I derive a second allocation threshold related to the product market distortion. Because the second threshold is unambiguously below the first it follows that efficiency in both markets cannot be achieved by means of permit allocation alone, confirming analyses by Misiolek and Elder (1989) and Disegni Eshel (2005).

The interplay between permit and product market is at the root of what is sometimes referred to as "windfall profits". This term is not well defined and can refer to unexpected profits in general, profits from a policy change or specifically the scarcity value created by regulation and embedded in grandfathered permits. Intuitively, if firms are able to pass pollution opportunity costs on to consumers but receive most (or all) permits for free, they essentially get reimbursed for costs they never had to incur. In this paper I show that it is possible for firms to profit from the introduction of a permit market even if they receive no free allocation at all.

Profits related to free distribution of permits have been identified as an issue in permit markets in general (Vollebergh et al. 1997; Bovenberg and Goulder 2000), and in particular in the EU ETS (Grubb and Neuhoff 2006; Hepburn et al. 2006; Neuhoff et al. 2006; Sijm et al. 2006; Smale et al. 2006). Such profits constitute a wealth transfer from consumers to firms but they do not impact efficiency directly ${ }^{1}$ nor affect the permit price in a competitive market. This no longer holds with imperfect competition, because a price-setting firm will take overall profits into account when making its production and permit purchase decisions, including such "windfall" profits.

The literature that is most closely related to my paper pertains to "raising rivals' cost" strategies, whereby a dominant firm influences its position in the product market indirectly via manipulation of input prices (e.g. an emissions permit price). However, no direct market power in the product market is assumed and the focus is on firms expanding their market share at the expense of the fringe rather than consumers.

1 There is a second-order impact on efficiency from distributing permits for free. The revenue from a Pigouvian tax (or from selling permits) should be used to lower existing distortionary taxes (for example income taxes) in order to minimize the overall deadweight loss of the tax system (Parry 1995; Bovenberg and Goulder 1996). This is generally known as the weak double dividend hypothesis. 
My results are not just of theoretical interest but have empirical relevance for two reasons: First, the assumption of market power in both markets seems appropriate: Assuming a firm has market power in the permit market, it almost certainly perceives market power in the product market as well if the latter is a subset of the former and competition from outside the system is limited (e.g. for electricity). Second, the largest players and thus the most likely candidates for price manipulation in the EU ETS are electricity producers, which were underprovided with permits relative to their past emissions. In the theory section I prove that net permit buyers can find it optimal to inflate the permit price upwards, given a sufficiently generous free allocation and cost pass-through in the output market. The applied section of this paper indicates that the largest electricity producers in Germany, the UK and the Nordpool market received a permit allocation that exceeds the allocation threshold for price manipulation. Taken together, my results imply that imperfect competition in both the permit and electricity market would have resulted in an inflation of both prices, thereby providing a possible explanation for the elevated permit price levels during the early months of the EU ETS.

\section{Literature of Market Power in Permit Markets}

One of the best-known results about market power in permit markets is Hahn (1984) finding that the permit price is an increasing function of the dominant firm's permit allocation. If the firm is a net buyer of permits, it will exert its power to decrease the permit price in order to minimize compliance costs, and vice versa. Although Hahn's paper is generally credited to be the seminar work, Sinn and Schmoltzi (1981) previously derived an equivalent result. ${ }^{2}$

Westskog (1996) extends the analysis to a Cournot model involving multiple firms and van Egteren and Weber (1996) allow for noncompliance, and they arrive essentially at the same conclusions. Liski and Montero (2005) examine banking behavior of a dominant firm and find that the firm exhausts its stock of banked permits slower than it would if it had no market power, and it does so by manipulating the permit price upwards. This is the intertemporal equivalent of Hahn's result.

Maeda (2003) develops a model with a dominant firm acting as a net seller, and a second dominant firm as well as the aggregate of the fringe as net buyers of permits. Again, market power is assumed to exist only in the permit but not the product market. Using linear marginal abatement costs and assuming that the two dominant firms engage in Nash bargaining, he argues that the permit price will never be below the "efficient" price, i.e. the price that would emerge if all firms were price takers. His results are therefore not fully equivalent to Hahn's, but they are driven by the rather specific model setup. If the only dominant firm is a net buyer, the fringe has an aggregate permit surplus and/or marginal abatement costs are nonlinear, the resulting price could fall below the efficient price.

The issue of market power in both permit and product markets is closely related to the literature pertaining to "raising rivals' costs" (Salop and Scheffman 1983, 1987; Krattenmaker and Salop 1986a,b; Hart and Tirole 1990; Ordover et al. 1990), henceforth referred to as RRC. The focus of this literature is that dominant firms may increase their market share and overall profits by artificially increasing industry costs, under the general assumption that these costs are lower for the dominant firm than for the fringe. The cost increase can take many forms, including the institution of mandatory standards, labeling, advertising etc, all

2 The reason why Hahn usually gets credit for the seminal work about market power in permit market may lie in the fact that Sinn and Schmoltzi published their work in German. 
of which are expected to be less costly on a per-output basis for the dominant firm than for the price-taking fringe. One particular version of RRC is to over-purchase necessary inputs of production (Salop and Scheffman 1987), which is a profitable strategy if the product price increase from this manipulation exceeds the firm's average cost increase.

A number studies have applied the theory of RRC to the context of a permit market, which can be understood as a necessary input for production. Misiolek and Elder (1989) set up a model where a dominant firm has market power in both markets, which enables it to increase rivals' costs in the product market via the permit price. This additional tool, which the authors call exclusionary manipulation, leads the firm to buy more permits than it would if it were focusing on compliance cost minimization alone (i.e. Hahn's case). In the monopoly case (i.e. a dominant net permit seller), the increased permit demand unambiguously leads to an increase in permit price distortion and a decrease in overall efficiency. However, in the case of a net permit buyer, price manipulation may result in a permit demand that is closer to the efficient level (as defined by the equality between the firm's marginal abatement costs and the permit price) than without the link between the two markets. If the exclusionary effect is very strong, ${ }^{3}$ it can lead the net buyer to push the permit price beyond the efficient level, which is qualitatively similar to my findings.

Von der Fehr (1993) extend the analysis to the case of two dominant firms that engage in Cournot behavior and focus on exclusionary manipulation, whereas Sartzetakis (1997a) addresses positioning (predatory) behavior based on RRC in emissions permit markets. He finds that the more stringent the environmental regulation, the more profitable RRC will be, and that welfare implications are ambiguous and depend on the production efficiency and emission intensity of the dominant firm relative to the fringe. In a different paper, the same author examines welfare implications under limited information and concludes that in spite of price manipulation, overall welfare is greater in a permit market than under command and control (Sartzetakis 1997b). The paper that is most closely related to mine is by Disegni Eshel (2005), who derives an efficiency condition that implicitly defines the socially efficient level of free allocation to the dominant firm, using the distortions in the permit and the product market as weights.

Although closely related to this literature, my paper differs in three key aspects. For one, the focus of my paper is different in that the dominant firm profits at the expense of consumers rather than that of the fringe. Even if the dominant firm expands its market share at the expense of the fringe, the fringe firms' profits may still increase as they effectively free-ride on the dominant firm's (costly) product price manipulation. Second, whether or not $\mathrm{RRC}$ is profitable for a firm depends on its costs relative to that of the fringe. As I show below, in my model even extremely pollution-intensive firms can find it profitable to push up the permit price, conditional on a sufficiently large free allocation. And third, none of these papers analytically derives a threshold of free allocation beyond which the dominant firm finds it profitable to increase the permit price.

As a complement to this theoretical literature, a number of experimental studies assess the empirical importance of different features of permit markets, including market power (Muller and Mestelman 1998). Godby (2002) tests Hahn's and Misiolek's theory in laboratory experiments and finds that it predicts actual outcomes better than a predictions based on competitive markets, and that the effect of market power may be significant. Brown-Kruse et al. (1995) carry out similar experiments and likewise find that market power matters,

3 The strength of the exclusionary manipulation effect is a function of the dominant firm's degree of market power in the permit market, the sensitivity of the fringe's product output to changes in the permit price, and the own-price elasticity of consumer demand and fringe supply. 
especially when the dominant firm engages in more than simply cost-minimizing manipulation but takes the product market into account.

\section{Model}

I set up a simple Stackelberg model of an industry sector containing $N$ firms that is subject to an emissions permit market. ${ }^{4}$ The cost function for firm $i \in N$ is described by $C^{i}\left(q_{i}, e_{i}\right)$, which depends on output $q_{i}$ and emissions $e_{i}$ and is continuous and twice differentiable in both arguments. Costs are increasing in output, decreasing in emissions and convex in both arguments, such that $C_{q}^{i}>0, C_{q q}^{i}>0, C_{e}^{i}<0, C_{e e}^{i}>0, C_{q e}^{i}<0$ and $C_{q q}^{i} C_{e e}^{i}-\left(C_{q e}^{i}\right)^{2}>0$. Without loss of generality I assume that firm 1 has market power in both the product and the permit market.

To study the equilibrium, I start by analyzing the behavior of firms $i=2, \ldots, N$ that comprise the price-taking fringe, before I move on to the dominant firm. The fringe's profit maximization problem is

$$
\begin{gathered}
\max _{q, e, x} \Pi_{i}=p q_{i}-C^{i}\left(q_{i}, e_{i}\right)-\left(x_{i}-\bar{x}_{i}\right) \sigma \\
\text { s.t. } e_{i} \leq x_{i}
\end{gathered}
$$

where $p$ is the product price, $\sigma$ the permit price, $x_{i}$ refers to permit purchases and $\bar{x}_{i}$ is firm $i$ 's free permit allocation. With a binding cap we can substitute the constraint into the objective function and arrive at the familiar first-order conditions that marginal production costs equal the product price, and marginal abatement costs equal the permit price. This implicitly defines the fringe's optimal production output, emissions and permit purchase decisions:

$$
\begin{aligned}
& p=C_{q}^{i}(\cdot) \quad \Rightarrow \quad q_{i}^{*}=q_{i}^{*}(p, \sigma) \\
& \sigma=-C_{e}^{i}(\cdot) \quad \Rightarrow \quad e_{i}^{*}=x_{i}^{*}=x_{i}^{*}(p, \sigma)
\end{aligned}
$$

The dominant firm takes (Eq. 2) into account when maximizing its own profits. It faces an inverse demand function and a permit market-clearing condition of

$$
\begin{aligned}
& p=P(Q)=P\left(q_{1}+\sum_{i=2}^{N} q_{i}^{*}(p, \sigma)\right) \\
& S=x_{1}+\sum_{i=2}^{N} x_{i}^{*}(p, \sigma)
\end{aligned}
$$

where $S$ is the overall emissions cap and $q_{1}$ and $x_{1}$ refer to the dominant firm's output and permit purchase decisions, respectively. This system of equations describes a fixed point with a mapping of $F\left[p\left(q_{1}, x_{1}\right), \sigma\left(q_{1}, x_{1}\right)\right] \rightarrow\left(p\left(q_{1}, x_{1}\right), \sigma\left(q_{1}, x_{1}\right)\right)$. A unique solution exists if the vector $(p, \sigma)$ belongs to a convex set (which is trivially true for prices), and $F[\cdot]$ is upper-semicontinuous and monotone, which is assured by the continuity and monotonicity of the demand function $P(Q)$ and the cost function $C^{i}\left(q_{i}, e_{i}\right)$.

4 This permit market may also include other sectors, but for simplicity I will confine the analysis to one sector. Note that the more sectors that are covered by the permit market, the less tenable is the assumption of market power in the permit but not the output market. 
From Eqs. 1-3 it follows that the product price and the permit price are both a function of the dominant firm's output and permit purchase decisions:

$$
\begin{aligned}
& p=p\left(q_{1}, x_{1}\right) \\
& \sigma=\sigma\left(q_{1}, x_{1}\right)
\end{aligned}
$$

The impact of the dominant firm's output and permit purchase decisions on the product and permit price can be derived by differentiating (Eq. 3) w.r.t. $q_{1}$ and $x_{1}$ and are summarized in the following Lemma:

Lemma 1 The dominant firm's output and permit purchase decisions will influence the product and permit prices jointly such that

$$
\begin{array}{ll}
\frac{\partial p}{\partial q_{1}}<0 ; & \frac{\partial p}{\partial x_{1}}>0 \\
\frac{\partial \sigma}{\partial q_{1}}<0 ; & \frac{\partial \sigma}{\partial x_{1}}>0
\end{array}
$$

The economic interpretation of the top left and bottom right relationships are straightforward (an increase in the monopolist's output reduces the output price, and an increase in the monopolist's permit demand increases the permit price), but the other two results need some more explanation. The relationship $\partial p / \partial x_{1}>0$ can be explained by splitting up the effect into three parts:

$$
\frac{\partial p}{\partial x_{1}}=\underbrace{\frac{\partial p}{\partial Q^{f}}}_{-} \cdot \underbrace{\frac{\partial Q^{f}}{\partial \sigma}}_{-} \cdot \underbrace{\frac{\partial \sigma}{\partial x_{1}}}_{+}>0 \text { where } Q^{f} \equiv \sum_{i=2}^{N} q_{i}
$$

By purchasing another permit, the dominant firm pushes up the permit price (the last term on the RHS). A higher permit price decreases the fringe's output (the second term), because (i) fringe firms equate marginal abatement costs with the permit price, (ii) equate marginal production costs with the product price and (iii) marginal production costs increase with abatement $\left(-C_{q e}>0\right)$. Lastly, the aggregate output contraction increases the permit price (the first term).

Similarly, the result on the bottom left in Lemma 1 is due to the reaction of the fringe and can be split up into

$$
\frac{\partial \sigma}{\partial q_{1}}=\underbrace{\frac{\partial \sigma}{\partial X^{f}}}_{+} \cdot \underbrace{\frac{\partial X^{f}}{\partial Q^{f}}}_{+} \cdot \underbrace{\frac{\partial Q^{f}}{\partial p}}_{+} \cdot \underbrace{\frac{\partial p}{\partial q_{1}}}_{-}<0 \quad \text { where } \quad X^{f} \equiv \sum_{i=2}^{N} x_{i}
$$

An increase in the dominant firm's output leads to a reduction in the product price (the last term on the RHS). Because fringe firms equate their marginal production costs to the product price, this will decrease the fringe's output (third term). Because $-C_{q e}>0$, a decrease in output translates to a decrease in marginal abatement costs such that the fringe demand for permits is reduced (second term), which in turn reduces the permit price.

The dominant firm's profit maximization problem and the resulting first-order conditions are 


$$
\begin{gathered}
\max _{q_{1}, x_{1}, e_{1}} \Pi_{1}=p\left(q_{1}, x_{1}\right) q_{1}-C^{1}\left(q_{1}, e_{1}\right)-\left(x_{1}-\bar{x}_{1}\right) \sigma\left(q_{1}, x_{1}\right)+\lambda\left(x_{1}-e_{1}\right) \\
p(\cdot)+\frac{\partial p}{\partial q_{1}} q_{1}-C_{q}^{1}(\cdot)-\left(x_{1}-\bar{x}_{1}\right) \frac{\partial \sigma}{\partial q_{1}}=0 \quad\left(q_{1}>0\right) \\
\frac{\partial p}{\partial x_{1}} q_{1}-\sigma(\cdot)-\left(x_{1}-\bar{x}_{1}\right) \frac{\partial \sigma}{\partial x_{1}}+\lambda=0 \quad\left(x_{1}>0\right) \\
-C_{e}^{1}(\cdot)=\lambda \\
x_{1} \geq e_{1} ; \quad \lambda \geq 0 ; \quad \lambda\left(X_{1}-e_{1}\right)=0
\end{gathered}
$$

The complementary slackness condition (Eq. 4d) implies that the constraint may not be binding, in which case the dominant firm holds more permits in equilibrium than it needs to cover its emissions.

The dominant firm's total marginal cost of buying a permit can be derived by combining Eqs. $4 \mathrm{~b}$ and $4 \mathrm{c}$ :

$$
-C_{e}^{1}(\cdot)=\sigma(\cdot)+\left(x_{1}-\bar{x}_{1}\right) \frac{\partial \sigma}{\partial x_{1}}-\frac{\partial p}{\partial x_{1}} q_{1}
$$

The RHS of Eq. 5 consists of the permit price itself, the cost increase in the permit market from buying an additional permit, (the second term) and the revenue effect in the product market (the third term). For a net permit seller, the last two terms are both negative and the firm's marginal abatement costs are unambiguously below the permit price. The firm will under-abate and sell fewer permits than if it were a price taker. This is qualitatively the same result as derived by Misiolek and Elder (1989).

For a net buyer of permits, the last two terms pull in opposite directions, implying that the relationship between its marginal abatement costs and the permit price depends on their relative magnitudes: If the additional revenue from buying another permit outweighs the cost increase in the permit market the firm sets its marginal abatement costs below the permit price, and vice versa. This means that it will under-abate and over-purchase permits relative to the situation where it perceives no price-setting power via its permit purchase decision (i.e. $\partial \sigma / \partial x_{1}=\partial p / \partial x_{1}=0$ ). Note that Eq. 5 only applies to price manipulation through the permit purchase pathway; both product and permit price could still be distorted relative to the situation of perfect competition through the dominant firm's output choice even if $-C_{e}^{1}=\sigma$.

If the revenue effect outweighs the compliance cost effect to the point where $-C_{e}^{1}=0$, then it will not abate at all and set $e_{1}=e_{1}^{B A U} \leq x_{1}$, with $e_{1}^{B A U}$ referring to business-as-usual (BAU) emissions in the absence of a permit market.

Equation 5 can be solved for the permit allocation to a net buyer where the two last terms cancel out and the firm sets its marginal abatement costs equal to the permit price:

$$
\bar{x}_{1}^{0}=x_{1}-\frac{\partial p / \partial x_{1}}{\partial \sigma / \partial x_{1}} q_{1}
$$

This quantity is unambiguously smaller than the firm's permit demand $x_{1}$. Combining Eqs. 6 and 5 implies that

$$
\begin{aligned}
> & -C_{e}^{1}<\sigma \\
\bar{x}_{1} & =\bar{x}_{1}^{0} \Rightarrow \begin{array}{l}
-C_{e}^{1}=\sigma \\
\\
<
\end{array} \quad C_{e}^{1}>\sigma
\end{aligned}
$$

Note that the firm's optimal permit purchase and product output decisions are a function of its allocation, such that the threshold (Eq. 6) is difficult to compute ex-ante, except for 
very simple functional forms of the cost function and the demand functions for permits and output. However, the threshold can be evaluated relatively easily ex-post when making some simplifying assumptions about consumer demand response (see below). ${ }^{5}$ Equations 6 and 7 lead to the following result:

\section{Result 1}

(a) If the dominant firm receives a free permit allocation equal to $\bar{x}_{1}^{0}$, it acts as a price taker in the permit market in the sense that it sets its marginal abatement costs equal to the permit price.

(b) If the dominant firm's allocation is greater than $\bar{x}_{1}^{0}$, it sets its marginal abatement costs below the permit price and manipulates the permit price upwards by over- purchasing permits and under-abating relative to the outcome under perfect competition in the permit market, and vice versa.

(c) The threshold allocation $\bar{x}_{1}^{0}$ is smaller than the firm's emissions and necessarily makes the firm a net buyer of permits.

Result 1 is the core finding of this paper and states that even if the dominant firm is a net buyer of permits it may find it profitable to manipulate the permit price upwards, provided that its allocation is sufficiently high.

Note that this is a generalization of Hahn's result, which I will denote $\bar{x}_{1}^{H} \equiv x_{1}$ : A dominant firm will only abstain from manipulating the price if it receives exactly the number of allowances necessary to cover its emissions and therefore does not trade. To see this, simply set $\partial p / \partial x_{1}=0$ in Eq. 6, thus eliminating the link between product and permit markets. Also note that if the second term in Eq. 6 is sufficiently large (i.e. if the effect of the firm's permit purchases on the product price is sufficiently large relative to the effect on the permit price, or if output is sufficiently large) then $\bar{x}_{1}^{0}<0$. In this case, even full auctioning will lead the firm to inflate the permit price.

Figures 1 and 2 contain a graphical illustration of this result. Figure 1 shows the situation where the dominant firm perceives market power in the permit market only (Hahn's model). The line marked by $M C_{1}^{H}=\sigma+\partial \sigma / \partial x_{1} *\left(x_{1}-\bar{x}_{1}\right)$ refers to the marginal costs of buying a permit and corresponds to the RHS of Eq. 5 without the last term. The increasing straight line represents the increasing relationship between the dominant firm's permit holdings and the permit price. With an initial allocation $\bar{x}_{1}^{B}$, the firm's marginal cost of buying a permit is below its marginal abatement costs $-C_{e}$, making the firm a net permit buyer. If it perceives no market power in the permit market it will equate its marginal abatement costs with the permit price and demand $x_{1}^{e}$ at a resulting price $\sigma^{e}$. However, noting that its permit demand affects the permit price, the firm will purchase fewer permits and move to the point $\left(x_{1}^{H B}, \sigma^{H B}\right)$ instead. This depresses the permit price relative to the efficient outcome.

Conversely, if the firm receives an initial allocation of $\bar{x}_{1}^{S}$ such that its marginal permit costs exceed its marginal abatement costs, it will sell fewer permits than if it had no market power and move to the point $x_{1}^{H S}, \sigma^{H S}$. The only way to cause the dominant firm to set its marginal abatement costs equal to the permit price is by giving it an initial allocation of $x_{1}^{e}$ (dashed line), in effect taking it out of the market.

Figure 2 shows the case of market power in the permit as well as the product market using the example of a net buyer. Total marginal costs of buying a permit, including the effect on the product market, are represented by the curve $M C_{1}^{D}=\sigma+\partial \sigma / \partial x_{1} *\left(x_{1}-\bar{x}_{1}\right)-\partial q / \partial x_{1} * q_{1}$

5 This caveat applies to some extent also to Hahn's results. Only if the firm's cost function is known can the regulator compute its efficient emissions and thus determine $\bar{x}_{1}^{H}$ ex ante. The difference is that in my setup, the regulator also needs to know the firm's degree of market power. 


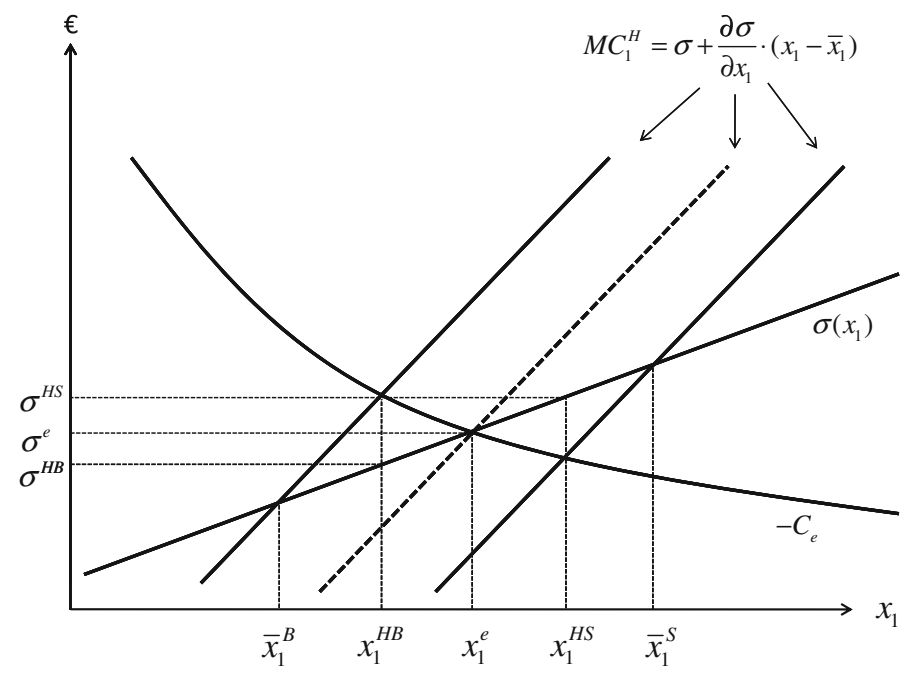

Fig. 1 Market power in permit market alone

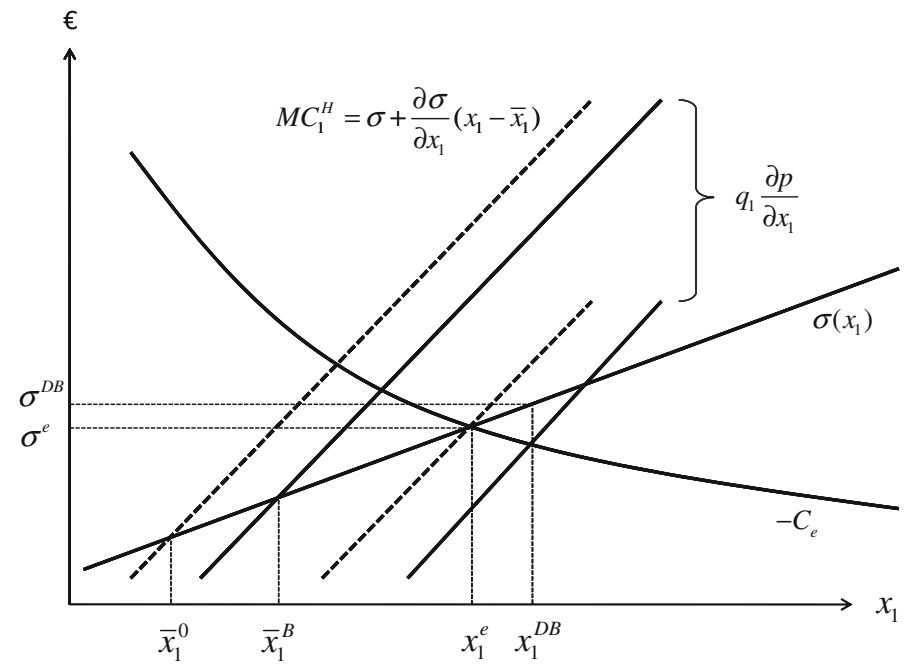

Fig. 2 Market power in permit market and output market

(the RHS of Eq. 5), which corresponds to a downward shift of $M C_{1}^{H}$. Equating its marginal abatement costs with $M C_{1}^{D}$, the firm chooses a permit demand of $x_{1}^{D B}>x_{1}^{e}$ with a corresponding price of $\sigma^{D B}>\sigma^{e}$. Due to the shift from $M C_{1}^{H}$ to $M C_{1}^{D}$, the firm inflates the permit price in spite of being a net permit buyer, because the revenue increase in the product market more than compensates it for the increased permit costs associated with this strategy. The figure graphically shows the meaning of the allocation threshold $\bar{x}_{1}^{0}$ : It is the amount of free permits that makes the firm choose demand $x_{1}^{e}$ at a price of $\sigma^{e}$, as indicated by the two dashed marginal cost curves.

So far I have focused on the effect of permit allocation on the permit price. However, the dominant firm's allocation also has an impact on the product price. I start by re-writing Eq. $4 \mathrm{a}$ as 


$$
p(\cdot)=C_{q}^{1}(\cdot)-\frac{\partial p}{\partial q_{1}} q_{1}+\left(x_{1}-\bar{x}_{1}\right) \frac{\partial \sigma}{\partial q_{1}}
$$

If the firm were a price taker it would equate its marginal production costs with the product price. The presence of market power in the product market increases the product price by the second term on the RHS, which is also a familiar result: A monopolist sets marginal cost equal to marginal revenue. The last term describes the effect of the firm's output decisions on the permit price. Because $\partial \sigma / \partial q_{1}<0$, this term decreases the product price if the firm is a net buyer of permits. Substituting Hahn's result of $\bar{x}_{1}^{H}=x_{1}$ would cancel the third term, but it would not remove the product price distortion introduced by the second term. The threshold allocation to the dominant firm that yields $p=C_{q}^{1}$ can be computed as

$$
\bar{x}_{1}^{00}=x_{1}-\frac{\partial p / \partial q_{1}}{\partial \sigma / \partial q_{1}} q_{1}
$$

In the Appendix A, I show that $\bar{x}_{1}^{00}<\bar{x}_{1}^{0}$. This leads to the following result:

Result 2 (a) If the dominant firm receives an allocation of $\bar{x}_{1}^{00}$, it will set its marginal production cost equal to the product price. If the firm receives an allocation that is greater than $\bar{x}_{1}^{00}$ it will set its marginal production costs below the product price by restricting output, and vice versa.

(b) The first-best solution where both the product and the permit price are at their competitive levels cannot be achieved by means of permit allocation alone because $\bar{x}_{1}^{00}<\bar{x}_{1}^{0}$.

(c) If the dominant firm receives more than $\bar{x}_{1}^{0}$ (less than $\bar{x}_{1}^{00}$ ) permits allocated for free, both the product and permit price will be distorted upwards (downwards) relative to marginal costs, leading to an increase in overall distortion and thus a decrease in overall efficiency. If the firm's allocation is $\bar{x}_{1}^{00}<\bar{x}_{1}<\bar{x}_{1}^{0}$, the product price will be increased whereas the permit price will be decreased relative to their competitive levels, and the overall effect on efficiency is ambiguous.

Results 1 and 2 imply that under the assumption of market power in both markets, the amount of free allocation is crucial for price distortion, and that a "neutral" allocation as implied by Hahn's result will result in an inflation of both the product and the permit price.

\section{Application to the EU ETS}

In this section, I apply my results to market data from the EU ETS and the German, UK and Nordpool power markets.

\subsection{The European Union Emissions Trading Scheme (EU ETS)}

In the following I describe the main features of the EU ETS. For a more detailed introduction to the market I refer the interested reader to Kruger and Pizer (2004) and the European Environment Agency's technical report (2006).

The EU ETS covers $\mathrm{CO}_{2}$ emissions from 6 broadly defined industry groups in all $27 \mathrm{EU}$ member countries. These sectors are power $\&$ heat, metals and coke ovens, oil refineries, glass $\&$ ceramics, cement $\&$ lime, and paper \& pulp. In the first phase, about 11,000 individual installations received a total of 2.1 billion EU allowances (EUAs) annually, mostly at no cost. One EUA gives the bearer a one-time right to emit one ton of $\mathrm{CO}_{2}$.

The market is organized into distinct multi-year periods called "phases". The first phase spanned the years 2005-2007 and was considered a pilot run for the second phase, which 
coincides with the Kyoto compliance period of 2008-2012. Pilot phase allowances could not be banked into the second phase and lost their value if unused for compliance. Future phases are currently expected to last seven years each, with no banking restrictions from one phase to the next but without official borrowing. However, because firms receive annual allowances in March of every year but don't have to surrender allowances until April, they can effectively bank and borrow allowances across time within a phase.

Firms can trade allowances freely within the EU. By April 31 of each year, firms have to surrender permits corresponding to their emissions in the previous calendar year. For every ton of $\mathrm{CO}_{2}$ emissions for which firms cannot surrender an allowance, they are fined a penalty consisting of $€ 40$ in the first phase and $€ 100$ in the second and third phase. In addition to paying the penalty, firms have to surrender the missing allowances in the following year. ${ }^{6}$

Jurisdiction in the EU ETS is divided between the EC and the member states. The latter submit detailed national allocation plans (NAPs) to the EC for every phase anew (i.e. the cap changes in every phase). This is a two-step procedure: First, member countries decide how much of their overall emissions reduction burden (as defined by their individual Kyoto commitments) they want to assign to the EU ETS sectors within their jurisdiction, with the remainder of the burden falling on other sectors such as transportation and households. In a second step, the allowances have to be distributed among the individual installations. All NAPs are reviewed by the EC in order to minimize competitive distortions among similar companies in different member states. ${ }^{7}$

The scheme is based on Directive 2003/87/EC, which became law on October 25, 2003. This left little time for firms and EU member countries to prepare for the market. In setting up the first-phase NAPs, countries were faced with the problem that they had very little information about firms' historic emissions. Unlike US power plants that were subject to emissions regulations since at least the mid 1990s, most firms in the EU never had to disclose their emissions of air pollutants, with some exceptions for local pollutants. The member countries addressed this lack of data by using industry projections generated by the firms themselves and reducing these estimates to counteract the obvious incentive problems associated with this procedure.

Permit allocations, trades and actual emissions are recorded in national registries run by each Member State, where all installations that are subject to the EU ETS have their individual accounts. The Central Administrator of the EU runs a central registry, called the Community Independent Transaction Log (CITL), which connects the 27 national registries and checks the recorded transactions for irregularities. It is the duty of member states to establish and/or verify firms' actual emissions by multiplying energy inputs with appropriate conversion factors.

Allocation by sector is shown in Fig. 3. Together, the power \& heat firms received nearly $70 \%$ of the total allocation. At the same time, this was the only sector with a net shortage of allowances, with all other sectors acting as net allowance suppliers (Fig. 4). ${ }^{8}$ In terms of installation size, about $90 \%$ of the covered firms are relatively small $(<1$ million ton $(\mathrm{Mt})$

\footnotetext{
6 Because firms can effectively bank and borrow allowances within a phase, in practice the penalty only applies at the end of each phase.

7 Although the Trading Directive lists as the scheme's explicit goals both least-cost compliance with the Kyoto targets and harmonization between member states, Boehringer and Lange (2005) show that both cannot be achieved simultaneously, given the constraint of free permit allocation. Thus, there is a tradeoff between efficiency and fairness in terms of a "level playing field" between firms in the same sector but located in different EU countries.

8 These are aggregate numbers; individually, there were power stations with an allowance surplus in 2005 and 2006 as well as firms in the other sectors that were permit demanders.
} 


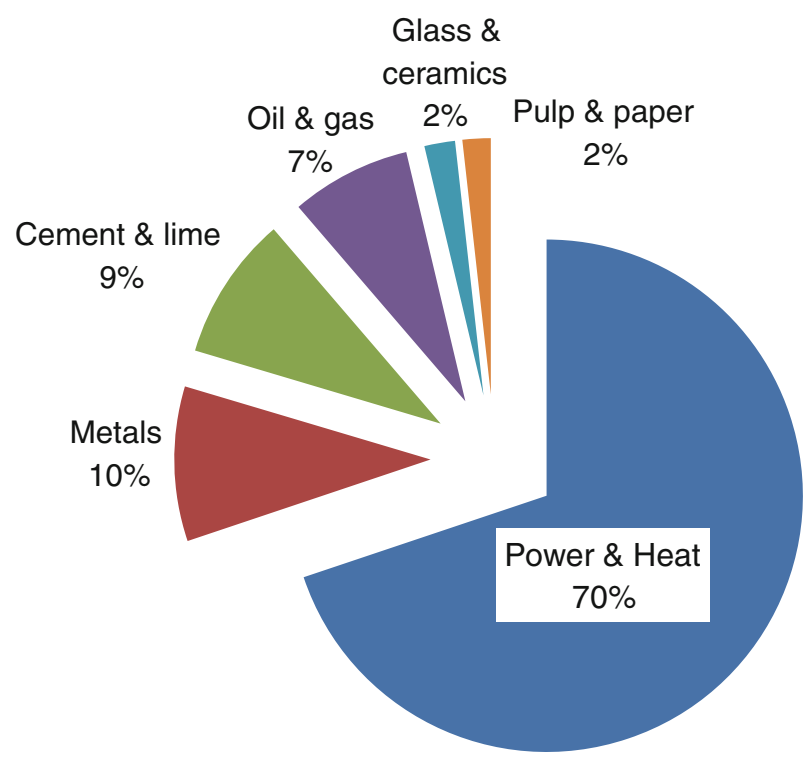

Fig. 3 Allocation by sector, 2005-2007

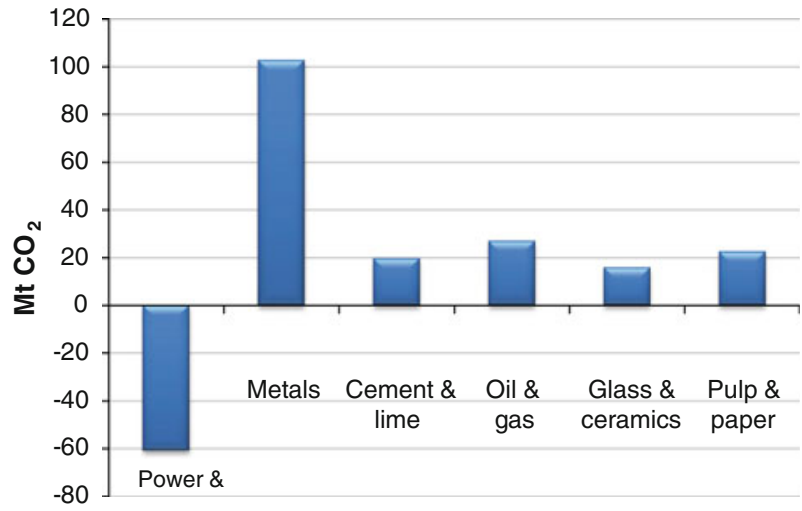

Fig. 4 Net position by sector (allocation minus emissions). Source: Community Independent Transaction $\log (C I T L)$

$\mathrm{CO}_{2}$ /year) and received about $19 \%$ of the total allocation. On the other extreme of the spectrum are the very large emitters (>10 Mt/year), which make up less than one percent of all installations in number but received more than a third of all allowances. Most of these large emitters are power plants.

Pre-market expectations of the allowance price were generally low, ${ }^{9}$ and the steep price increase took many observers by surprise. Figure 5 depicts the EUA price during Phase I.

\footnotetext{
9 In a simulation-based analysis of the EU ETS, Reilly and Paltsev (2005) calculated market-clearing marginal abatement costs to be $€ 0.6-0.9$ for their base scenario, with prices in even the most extreme scenarios below $€ 7$. Medium price estimates by brokers were somewhat higher, around of $€ 5.00$ for the first phase (PEW Center on Global Climate Change 2005). The European Emissions Trading Scheme (EU-ETS); Insights and Opportunities: 20.
} 


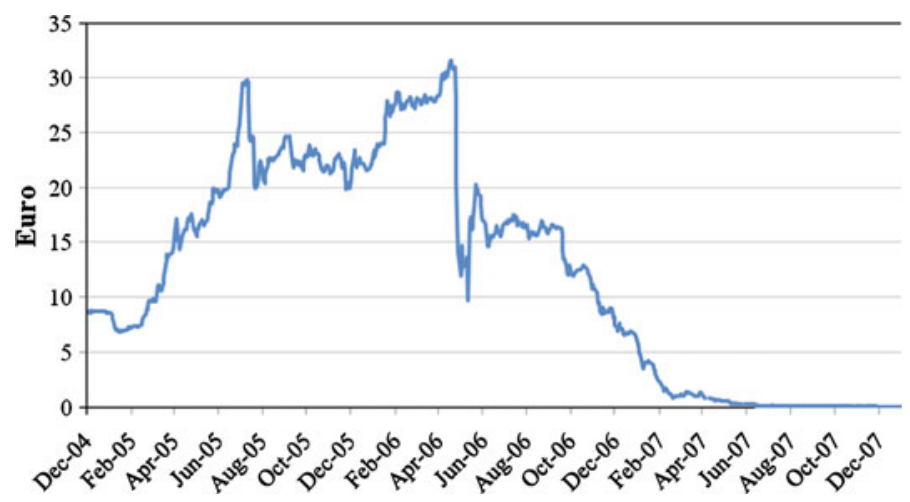

Fig. 5 EUA price during first phase

For over a year, the allowance price was above $€ 20$, and at its peak it surpassed $€ 31$ in April 2006. The price crash soon thereafter was triggered by the first round of emissions verifications, which revealed that aggregate 2005 emissions were $94 \mathrm{Mt}$ below the cap. ${ }^{10}$ The second round of emissions verifications in May 2007 again found an allowance surplus, but this no longer had a significant impact since prices had decreased to a few cents. Liquidity was overall high, and a significant amount of the total allocation was traded even in the first year.

Aggregate emissions in all three years of the pilot phase were below the total allocation. An emissions cap can turn out to be non-binding due to over-abatement and/or over-allocation. Without the possibility of banking, abating more than necessary in the first period and using the freed-up allowances for compliance in later periods with a tighter cap is not a profitable strategy. On the other hand, market participants had no way of knowing that the cap would turn out not to be binding while the price was high, so some abatement may have occurred during the first part of the phase. A market analysis by Ellerman and Buchner (2008) implies that at least a part of the gap between emissions and allocation was due to abatement.

\subsection{Empirical Approach}

There is evidence that the power \& heat sector received significant profits from the high allowance price due to a combination of free allocation and cost pass-through (Grubb and Neuhoff 2006; Hepburn et al. 2006; Neuhoff et al. 2006; Sijm et al. 2006). According to market observers (e.g. Point Carbon), it was the sustained allowance purchases from power $\&$ heat, combined with a relatively short allowance supply from the other sectors, that drove the price to the-in hindsight-very high level. There are a number of very large power producers for which the assumption of some market power seems plausible. Note that it is not necessary for the dominant firm to have complete market power in the sense that it can choose any $p$ and $\sigma$. All that is needed to generate the results of the theory section is that

\footnotetext{
10 Emissions verification numbers were supposed to be announced in May, but in late April leaked reports indicated that Belgium, France, the Czech Republic, the Netherlands and Estonia had allowance surpluses and that the allowance shortage in Spain was much smaller than anticipated, triggering the price crash. By early May, the market was found to be $63.6 \mathrm{Mt}$ long, with 21 countries reporting. The announcement of the largest single country surplus in Poland did not affect prices very much.
} 
prices are sensitive to the dominant firm's permit purchase and output supply decisions such that $\partial \sigma / \partial x_{1}>0$ and $\partial p / \partial q_{1}<0$.

The main difficulty to apply (Eq. 6) to empirical work is that the effect of a dominant firm's permit purchase decisions on the output and the permit price is generally unknown. In order to work around this problem I will introduce the following corollary to Result 1 :

Corollary If the dominant firm receives a permit allocation in excess of $\bar{x}_{1}^{0}$, it will increase its market share at the expense of the fringe, and vice versa. If it receives exactly $\bar{x}_{1}^{0}$, its market share will remain unchanged relative to the situation without regulation.

The proof follows directly from Eq. 6 and the assumption that marginal production costs decrease in emissions, i.e. $C_{q e}^{1}<0$. If the dominant firm is over-allocated relative to the threshold, its marginal abatement costs will be lower, its emissions greater and its marginal costs of production smaller than if it had received the neutral allocation $\bar{x}_{1}^{0}$, leading to an increase in output relative to the fringe. The opposite is true if it receives $\bar{x}_{1}<\bar{x}_{1}^{0}$. The corollary is consistent with the results from the Raising Rivals' Cost literature, where the dominant firm increases profits by pushing up industry input prices and expanding its market share at the expense of the fringe.

Because the introduction of a permit market will increase the product price and therefore reduce consumer demand, the dominant firm's absolute (as opposed to relative) output change depends on the magnitude of consumer demand and the firm's allocation. If the demand decrease is large, $d q_{1}$ could be negative even if $\bar{x}_{1}>\bar{x}_{1}^{0}$, because the increase in market share may not make up for the decrease in output due to reduced demand. On the other hand, if there is no or very little demand response, then an increase in market share translates to $d q_{1}>0$. For $\bar{x}_{1} \leq \bar{x}_{1}^{0}$, it must be that $d q_{1}<0$ regardless of the relative importance of market share change and demand response, because both effects decrease the dominant firm's output.

The introduction of the EU ETS did not seem to significantly impact electricity consumption in the three markets in question. Table 1 shows the results from a least-squares regression of monthly electricity consumption through June 2006 on a set of monthly dummies, a quadratic time trend, average monthly temperature and a dummy that is zero before and one after the introduction of the EU ETS (January 2005). The latter is not significant at $p=0.05$ for any market. For the Nordic market, the coefficient is significant at $p=0.06$ but positive rather than negative. Possible reasons for a very low short-term demand response include the fact that the most efficient means to reduce electricity use is to make changes in industrial production equipment or the portfolio of household appliances towards increased energy efficiency, both of which takes time.

Because of the small (if any) demand response, I will make the assumption that

$$
\begin{aligned}
& \bar{x}_{1}>\bar{x}_{1}^{0} \Rightarrow d q_{1} \geq 0 \\
& \bar{x}_{1} \leq \bar{x}_{1}^{0} \Rightarrow d q_{1}<0
\end{aligned}
$$

This allows me to replace the (unobservable) ratio in Eq. 6 with $d p / d \sigma$, the degree to which permit costs are passed through to the output price. Totally differentiating $p$ and $\sigma$ gives

$$
\frac{d p}{d \sigma}=\frac{\partial p / \partial x_{1} * d x_{1}+\partial p / \partial q_{1} * d q_{1}}{\partial \sigma / \partial x_{1} * d x_{1}+\partial \sigma / \partial q_{1} * d q_{1}}=\frac{\partial p / \partial x_{1}}{\partial \sigma / \partial x_{1}} \quad \begin{array}{r}
d q_{1}>0 \\
\text { if } d q_{1}=0 \\
d q_{1}<0
\end{array}
$$


Table 1 Impact of EU ETS on aggregate electricity demand for Germany, UK and Nordpool markets

\begin{tabular}{|c|c|c|c|c|c|c|}
\hline \multirow{2}{*}{$\begin{array}{l}\text { Dependent variable } \\
\text { Electr. cons. (GWh) }\end{array}$} & \multicolumn{2}{|l|}{ Germany } & \multicolumn{2}{|l|}{ UK } & \multicolumn{2}{|l|}{ Nordpool } \\
\hline & Coefficient & $t$ Stat & Coefficient & $t$ Stat & Coefficient & $t$ Stat \\
\hline EU ETS & 0.333 & 0.60 & 0.153 & 0.78 & 0.664 & 1.95 \\
\hline Period & -0.056 & -2.29 & 0.193 & 6.06 & 0.099 & 6.60 \\
\hline Periodsq & 0.0003 & 2.44 & -0.0006 & -5.85 & -0.0003 & -4.66 \\
\hline Jan & 2.076 & 3.92 & 1.166 & 4.93 & 1.237 & 3.75 \\
\hline $\mathrm{Feb}$ & -1.911 & -3.61 & -2.600 & -11.05 & -2.352 & -7.02 \\
\hline Mar & 0.748 & 1.27 & -0.386 & -1.58 & -0.646 & -1.99 \\
\hline Apr & -3.130 & -4.15 & -3.563 & -12.34 & -4.422 & -11.27 \\
\hline May & -3.326 & -3.33 & -3.527 & -9.46 & -5.028 & -9.58 \\
\hline Jun & -4.065 & -3.45 & -4.231 & -8.51 & -6.585 & -9.94 \\
\hline Jul & -2.729 & -2.22 & -3.047 & -5.44 & -6.519 & -8.64 \\
\hline Aug & -3.514 & -2.88 & -3.289 & -5.96 & -4.875 & -6.61 \\
\hline Sep & -3.451 & -3.50 & -3.557 & -7.63 & -5.300 & -9.07 \\
\hline Oct & -0.750 & -0.97 & -1.543 & -4.42 & -2.658 & -6.16 \\
\hline Nov & -0.154 & -0.27 & -0.895 & -3.64 & -1.607 & -4.69 \\
\hline Temp $^{\mathrm{a}}$ & -0.122 & -3.58 & -0.148 & -6.58 & -0.197 & -9.30 \\
\hline Cons & 55.343 & 33.59 & 22.317 & 8.23 & 36.401 & 35.54 \\
\hline Data range $^{b}$ & \multicolumn{2}{|c|}{ 1/1996-12/2007 } & \multicolumn{2}{|c|}{$4 / 2001-12 / 2007$} & \multicolumn{2}{|c|}{$1 / 1996-12 / 2007$} \\
\hline$N$ & \multicolumn{2}{|l|}{144} & \multicolumn{2}{|l|}{81} & \multicolumn{2}{|l|}{144} \\
\hline$R 2$ & \multicolumn{2}{|l|}{0.89} & \multicolumn{2}{|l|}{0.98} & \multicolumn{2}{|l|}{0.98} \\
\hline
\end{tabular}

a Average temperature in Fahrenheit for Munich (Germany), London (UK) and the average of Stockholm, Copenhagen and Helsinki (Nordpool)

$\mathrm{b}$ Based on availability of consistently defined historic consumption

To derive the inequalities in Eq. 11, multiply both sides by $\left(\partial \sigma / \partial x_{1}\right) /\left(\partial p / \partial x_{1}\right)>0$, re-arrange and use the result derived in Appendix A.2. Combining Eqs. 10 and 11 shows that the empirical threshold

$$
\begin{aligned}
\tilde{x}_{1}^{0} \equiv x_{1}-\frac{d p}{d \sigma} q_{1} & \geq \bar{x}_{1}^{0} \quad \text { if } \quad x_{1}>\bar{x}_{1}^{0} \quad\left(d q_{1} \geq 0\right) \\
& <\bar{x}_{1}^{0} \quad \text { if } \quad x_{1} \leq \bar{x}_{1}^{0} \quad\left(d q_{1}<0\right)
\end{aligned}
$$

is conservative in the sense that if it is found to be exceeded, the true threshold will also be exceeded, and vice versa. The empirical threshold (Eq. 12) can be evaluated using market data and compared to firms' actual allocation, which is the subject of the next subsection.

It has to be noted that except for very simple functional forms, it is not possible to evaluate (Eq. 12) ex ante, because the firm's optimal permit demand $x_{1}$ (or emissions $e_{1}$ ) cannot be computed. However, after actual output and emissions are observed, it is possible to assess whether $\bar{x}_{1}^{0}$ was exceeded.

\subsection{Application to German, UK and Nordpool Electricity Markets}

The average output price increase due to a permit price increase, $d p / d \sigma$, depends on the cost pass-through rate and the emission intensity of the marginal generator at each point in time. 
Table 2 Estimates for $\mathrm{dp} / \mathrm{d} \sigma$

\begin{tabular}{llll}
\hline & Peak $^{\mathrm{a}}$ & Off-peak $^{\mathrm{a}}$ & Weighted average $^{\mathrm{b}}$ \\
\hline Germany & 0.57 & 0.51 & 0.55 \\
UK & 0.29 & 1.00 & 0.53 \\
Nordpool & & 0.62 \\
\hline
\end{tabular}

${ }^{\text {a }}$ Peak and off-peak last 12 hours each per day

${ }^{\mathrm{b}}$ Average computed as $(2 *$ peak + off-peak)/3 for UK and DE

The cost pass-through rate is the proportion of emission (opportunity) costs of the pricesetting generator that are passed through to consumers. It depends on the price elasticity of consumer demand and the extent to which an industry is exposed to imports from regions with no emission costs. For electricity, the cost pass-through rate is generally considered to be close to $100 \%$, because of low demand elasticity and almost complete protection from imports from outside of the EU.

The emission intensity is largely determined by the fuel used for generation and ranges from zero for hydroelectric, wind and nuclear power to about $0.4 \mathrm{tCO}_{2}$ per $\mathrm{MWh}$ of electricity for combined-cycle gas turbines (CCGT), $0.95 \mathrm{tCO}_{2} / \mathrm{MWh}$ for pulverized hard coal and $1.18 \mathrm{tCO}_{2} / \mathrm{MWh}$ for lignite. ${ }^{11}$ During the year, many different generators are the margin for some time.

The term $d p / d \sigma$ is the volume-weighted average of the product of cost pass-through rate and the emission intensity. Because generation portfolios vary across regions and there are transmission constraints, $d p / d \sigma$ varies even across integrated electricity markets. Table 2 presents estimates for $d p / d \sigma$ for Germany and the UK based on OLS results by Sijm et al. (2008), ${ }^{12}$ and for the Nordpool market based on a cointegration analysis by Fell (2008). The table entries imply that if the permit price increases by $€ 1$, the electricity price in these markets increases on average by $€ 0.52-€ 0.62$ per MWh.

Table 3 lists emissions, output, emission intensity, allocation and $\tilde{x}_{1}^{0}$ for the largest electricity producers in Germany, the UK and Nordpool. In Germany, the four largest firms combine for about three quarters of the country's generation capacity. Together, they received 799 million allowances allocated for free and emitted $832 \mathrm{Mt} \mathrm{CO}_{2}$ during the first phase of the market, implying a free allocation ratio of $96 \%$. All firms obtained an allocation in excess of the empirical threshold (Eq. 12), in some cases significantly so. For firms that produce a large share of their output using carbon-free technologies such as nuclear and hydro, the relatively low emission intensity translates to a negative value for $\tilde{x}_{1}^{0}$, meaning that these firms would be over-allocated relative to this threshold even with zero free allocation (i.e. full auctioning).

In the UK, the market is somewhat less concentrated. The largest five electricity producers received a total of 213 million allowances and emitted $283 \mathrm{Mt} \mathrm{CO}_{2}$, which translates to an allocation ratio of $75 \%$. Although UK firms received a relatively smaller free allocation than their German counterparts, the threshold (Eq. 12) was nevertheless exceeded for every firm.

11 These are average values. For each technology, emission factors vary to some extent, depending on plant age and subtype.

12 They used $0.973 \mathrm{tCO}_{2} / \mathrm{MWh}$ for coal (peak and off-peak in Germany, off-peak in UK) and $0.367 \mathrm{tCO} 2 / \mathrm{MWh}$ for CCGT (peak in UK); see Sijm et al. (2008, Table 4.2). 
Table 3 Emissions, output and permit allocation of select EU power firms

\begin{tabular}{|c|c|c|c|c|c|c|}
\hline & $\begin{array}{l}\text { Emissions }^{\mathrm{a}} \\
\left(\mathrm{Mt} \mathrm{CO}_{2}\right)\end{array}$ & $\begin{array}{l}\text { Output }^{\mathrm{b}} \\
\text { (TWh) }\end{array}$ & $\begin{array}{l}\rho^{\mathrm{b}} \\
\left(\mathrm{tCO}_{2} / \mathrm{MWh}\right)\end{array}$ & $\begin{array}{l}\text { Allocation }{ }^{\mathrm{a}} \\
\mathrm{Mt}\left(\mathrm{CO}_{2}\right)\end{array}$ & $\begin{array}{l}\tilde{x}_{1}^{0} \\
(\mathrm{Mt} \mathrm{CO} 2)\end{array}$ & Alloc./Em. \\
\hline \multicolumn{7}{|l|}{ Germany } \\
\hline RWE & 457 & 546 & 0.836 & 428 & 156 & 0.94 \\
\hline Vattenfall & 224 & 300 & 0.746 & 233 & 59 & 1.04 \\
\hline E.ON & 120 & 296 & 0.405 & 111 & -43 & 0.93 \\
\hline EnBW & 31 & 128 & 0.241 & 28 & -40 & 0.91 \\
\hline Total & 832 & 1,270 & 0.655 & 799 & 133 & 0.96 \\
\hline \multicolumn{7}{|l|}{$U K$} \\
\hline Powergen (E.ON) & 83 & 114 & 0.729 & 66 & 23 & 0.79 \\
\hline Npower (RWE) & 66 & 104 & 0.640 & 48 & 11 & 0.72 \\
\hline EdF & 61 & 73 & 0.832 & 37 & 22 & 0.60 \\
\hline Scottish power & 47 & 72 & 0.648 & 38 & 8 & 0.82 \\
\hline Scottish \& South. & 26 & 131 & 0.196 & 25 & -44 & 0.97 \\
\hline Total & 283 & 494 & 0.573 & 213 & 21 & 0.75 \\
\hline \multicolumn{7}{|l|}{ Nordpool } \\
\hline Dong & 44 & 46 & 0.961 & 43 & 16 & 0.98 \\
\hline Fortum & 20 & 156 & 0.130 & 19 & -76 & 0.96 \\
\hline Pojohla Voima & 14 & 48 & 0.299 & 16 & -15 & 1.10 \\
\hline Vattenfall & 17 & 355 & 0.048 & 15 & -203 & 0.88 \\
\hline Total & 96 & 605 & 0.159 & 94 & -279 & 0.97 \\
\hline
\end{tabular}

a Emissions and allocation taken from Community Independent Transaction Log (CITL), except for RWE and Pojohla Voima where this information is given in the annual reports

${ }^{b}$ Output from annual reports, except for E.ON, EnBW and Scottish Power, which do not provide this information. For these firms, the computation relies on the emission factor $\rho$, which is either given explicitly or implicitly in business reports

Finally, the four largest EU firms within the Nordpool power market ${ }^{13}$ received a total of 94 million allowances during the first phase, compared to emissions of $96 \mathrm{Mt}$ with a ratio of 97\%. Again, all firms were over-allocated with respect to the threshold $\tilde{x}_{1}^{0}$.

Even allowing for some imprecision due to the simplifying assumptions required for the empirical analysis, these results indicate that conditional on having market power, the largest electricity producers in these countries would have found it profitable to manipulate the permit price upwards because the increased profits from permit price manipulation in the output market more than compensate them for the increased compliance costs.

Another noteworthy result is that for a number of firms, the threshold is negative, meaning that they would have been interested in permit price inflation even without free allocation. With full cost pass-through, the electricity price increases by the carbon costs of the marginal generator, but the price increase applies to the entire output. Firms with a lower emission intensity than the average marginal generator profit from the institution of a permit market even if they have to purchase all emission rights, because their revenue increase due to the electricity price increase more than compensates them for their compliance costs.

13 Norway is not in the EU and was therefore not covered by the EU ETS during the first phase. For the second phase, Norway linked its domestic permit market to that of the EU. 


\section{Conclusions}

There is a sizable literature about market power in permit markets, but to my knowledge, but with the exception of Disegni Eshel (2005), no paper has explicitly addressed the effect of free allocation on price manipulation in the presence of explicit market power in both permit market as well as the linked output market. Besides being of general economic interest, this particular question is motivated by a high (in hindsight too high) allowance price level during the first phase of the EU ETS, which reportedly led to large gains especially for firms in the power \& heat sector. These firms received most of their allowances for free but were able to pass through a large part of the carbon-related opportunity costs to consumers. The presence of large gains from the introduction of the permit market combined with the history of imperfect competition in the power \& heat sector raises the question whether dominant power producers could have used their market weight in order to increase the permit price to maximize overall profits.

According to the results derived by Sinn and Schmoltzi (1981) and Hahn (1984), the answer to this question is "no", because on aggregate the power sector was the only net buyer in the permit market. In their framework, any dominant permit buyer would depress rather than inflate the permit price, and would act competitively only when given the amount of free allocation that exactly covers its emissions if it were to set its marginal abatement costs equal to the permit price.

In this paper, I analytically derive a threshold of free allocation in the presence of imperfect competition in both markets, above which a dominant firm finds it profitable to inflate the permit price by under-abating and over-purchasing permits. This threshold is less than the firm's emissions were it to set its marginal abatement costs equal to the permit price, and necessarily makes the firm a net permit buyer.

My theoretical results are not subject to stringent assumptions about relative efficiency in production and/or abatement among firms, as is typically the case in the raising rivals' costs literature and the paper by Disegni Eshel (2005). Even a firm with a higher carbon intensity than the average marginal generator can find it profitable to increase the permit price if its free allocation is large enough. Moreover, while the dominant firm will profit at the expense of the fringe to some extent by increasing its market share, the main source of profit is the receipt of free permits coupled with cost pass-through to consumers via the increased product price. In fact, the industry fringe profits from market manipulation on behalf of the dominant firm because its windfall profits from receiving free permits increase with the permit price.

In order to apply my results to the EU ETS, I propose an operational threshold that is a function of the average amount of cost pass-through in the electricity market as well as firms' permit holdings and output. I find that the largest electricity producers in Germany, the UK and the Nordpool market received an allocation well in excess of this threshold. My results indicate that imperfect competition in both the permit and electricity markets (if it exists) would have resulted in an upward manipulation of the allowance price. As such, it is a possible explanation for the elevated allowance price level during the first 18 months of the EU ETS.

An important caveat to my paper is that I present no evidence that EU firms are in fact able to manipulate either the permit or the output price. Given the size of the market, a strict interpretation of market power as proposed by Maeda (2003) might conclude that even the largest firms are too small to yield price-setting power. However, considering that during much of the first phase the most active players in the EU ETS were power generators looking to cover their emissions and lock in profits on the futures market, whereas many smaller firms with a permit surplus were not trading until later, it is quite possible that large power 
producers' share in the subset of permits that were actually brought to market was enough to confer some degree of market power. This "practical" as opposed to theoretical market power would have vanished when more permit suppliers entered the market after the first round of emissions verification.

The policy implications of my results are the following. On efficiency grounds, the regulator should ensure that free permit allocation to potentially price-manipulating firms be in the range $\bar{x}_{1}^{00}<\bar{x}_{1}<\bar{x}_{1}^{0}$. In theory, one could pinpoint the optimal permit allocation by considering the welfare implications of the distortions in each market, an approach followed by Disegni Eshel (2005). However, this is not very practical since neither the firms' actual permit demand nor the resulting market distortions are known ex-ante.

To obtain an actual policy recommendation, first note that $\bar{x}_{1}^{00}$ is likely to be negative. Compared to carbon costs even during the high-price period of the first EU ETS, the gains from manipulating the electricity market are simply too large in order for permit allocation to turn a dominant firm into a price taker in the product market, especially considering that carbon costs are passed largely through to consumers. Provided that the permit allocation cannot be negative, the probability of $\bar{x}_{1}<\bar{x}_{1}^{00}$ is negligible.

Second, $\bar{x}_{1}^{0}$ is not known ex-ante and has to be estimated with considerable uncertainty, and for some firms it even turned out to be negative ex post. The uncertainty and possible negative sign of $\bar{x}_{1}^{0}$ imply that the probability of free allocation to firms with potential market power to fall within $\bar{x}_{1}^{00}<\bar{x}_{1}<\bar{x}_{1}^{0}$ is maximized at zero free allocation. This is equivalent to full auctioning.

However, even with auctioning both markets will generally remain distorted, since no amount or method of allocation can restore the first-best policy outcome in the presence of imperfect competition in two markets. If full auctioning indeed leads to $\bar{x}_{1}^{00}<\bar{x}_{1}<\bar{x}_{1}^{0}$ for dominant firms as desired, the resulting auction price for allowances will be below the level associated with perfect competition.

\section{A Appendix}

\section{A.1 Proof of Lemma 1}

Proof Differentiating (Eq. 2) with respect to $p$ and rearranging gives

$$
\left[\begin{array}{ll}
C_{q q}^{i} & C_{q e}^{i} \\
C_{q e}^{i} & C_{e e}^{i}
\end{array}\right]\left[\begin{array}{l}
\partial q_{i} / \partial p \\
\partial e_{i} / \partial p
\end{array}\right]=\left[\begin{array}{l}
1 \\
0
\end{array}\right]
$$

Solving for the effect of a price change on output and emissions yields

$$
\begin{aligned}
\frac{\partial q_{i}}{\partial p} & =\frac{C_{e e}^{i}}{\Delta^{i}}>0 \\
\frac{\partial e_{i}}{\partial p} & =\frac{-C_{q e}^{i}}{\Delta^{i}}>0 \text { with } \Delta^{i} \equiv C_{q q}^{i} C_{e e}^{i}-\left(C_{q e}^{i}\right)^{2}>0
\end{aligned}
$$

Similarly, differentiating (Eq. 2) w.r.t. the permit price gives

$$
\begin{array}{r}
\frac{\partial q_{i}}{\partial \sigma}=\frac{C_{q e}^{i}}{\Delta^{i}}<0 \\
\frac{\partial e_{i}}{\partial \sigma}=\frac{-C_{q q}^{i}}{\Delta^{i}}<0
\end{array}
$$


To analyze the effect of the dominant firm's output on output price $p$ and permit price $\sigma$, differentiate (Eq. 3) w.r.t. $q_{1}$ and rearrange:

$$
\left[\begin{array}{c}
P^{\prime} \sum_{i=2}^{N} \frac{\partial q_{i}}{\partial \sigma}\left(P^{\prime} \sum_{i=2}^{N} \frac{\partial q_{i}}{\partial p}-1\right) \\
\sum_{i=2}^{N} \frac{\partial x_{i}}{\partial \sigma} \sum_{i=2}^{N} \frac{\partial x_{i}}{\partial p}
\end{array}\right]\left[\begin{array}{l}
\frac{\partial \sigma}{\partial q_{1}} \\
\frac{\partial p}{\partial q_{1}}
\end{array}\right]=\left[\begin{array}{l}
-P^{\prime} \\
0
\end{array}\right]
$$

Solving for the effect of $q_{1}$ on the permit price:

$$
\frac{\partial \sigma}{\partial q_{1}}=\frac{-P^{\prime} \sum_{i=2}^{N} \frac{\partial x_{i}}{\partial p}}{\sum_{i=2}^{N} \frac{\partial x_{i}}{\partial \sigma}+P^{\prime} *\left[\sum_{i=2}^{N} \frac{\partial q_{i}}{\partial \sigma} \sum_{i=2}^{N} \frac{\partial x_{i}}{\partial p}-\sum_{i=2}^{N} \frac{\partial q_{i}}{\partial p} \sum_{i=2}^{N} \frac{\partial x_{i}}{\partial \sigma}\right]}
$$

Because $P^{\prime}<0$ and $e_{i}=x_{i}$ for $i=(2, \ldots, \mathrm{N})$, it follows immediately from Eq. A1 that the numerator is positive. The first term of the denominator is negative from Eq. A2. In order to show that Eq. A4 is negative I have to show that the term in the brackets is positive, i.e. that

$$
\Phi \equiv \sum_{i=2}^{N} \frac{\partial q_{i}}{\partial \sigma} \sum_{i=2}^{N} \frac{\partial x_{i}}{\partial p}-\sum_{i=2}^{N} \frac{\partial q_{i}}{\partial p} \sum_{i=2}^{N} \frac{\partial x_{i}}{\partial \sigma} \stackrel{?}{>} 0
$$

Substituting Eqs. A1 and A2, this is equivalent to showing that

$$
\sum_{i=2}^{N} \frac{C_{q e}^{i}}{\Delta^{i}} \sum_{i=2}^{N} \frac{-C_{q e}^{i}}{\Delta^{i}}-\sum_{i=2}^{N} \frac{C_{e e}^{i}}{\Delta^{i}} \sum_{i=2}^{N} \frac{-C_{q q}^{i}}{\Delta^{i}} \stackrel{?}{>} 0
$$

to prove the inequality in Eq. A5. Separating out the a single firm, it is clear that

$$
\frac{C_{q q}^{i} C_{e e}^{i}}{\left(\Delta^{i}\right)^{2}}-\frac{\left(C_{q e}^{i}\right)^{2}}{\left(\Delta^{i}\right)^{2}}=\frac{1}{\Delta^{i}}>0
$$

which enables me to express (Eq. A6) as

$$
\frac{1}{\Delta^{i}}+\sum_{\substack{i=2 \\ i \neq j}}^{N} \frac{C_{q q}^{i} C_{e e}^{j}-C_{q e}^{i} C_{q e}^{j}}{\Delta^{i}} \stackrel{?}{>} 0
$$

Noting the symmetry between $i / j$ and $j / i$ multiplications and dropping the first (positive) term, I can express this as

$$
\sum_{2 \leq i<j}^{N} \frac{C_{q q}^{i} C_{e e}^{j}+C_{q q}^{j} C_{e e}^{i}-2 C_{q e}^{i} C_{q e}^{j}}{\Delta^{i}} \stackrel{?}{>} 0
$$

Squaring both sides of the numerator in Eq. A7 yields

$$
\left(C_{q q}^{i} C_{e e}^{j}\right)^{2}+2 C_{q q}^{i} C_{e e}^{j} C_{q q}^{j} C_{e e}^{i}+\left(C_{q q}^{j} C_{e e}^{i}\right)^{2} \stackrel{?}{>} 4 C_{q q}^{i} C_{e e}^{i} C_{q q}^{j} C_{e e}^{j}>4\left(C_{q e}^{i} C_{q e}^{j}\right)^{2}
$$

where the second inequality comes from the fact that

$$
C_{q q}^{i} C_{e e}^{i}>\left(C_{q e}^{i}\right)^{2} \forall i \Rightarrow C_{q q}^{i} C_{e e}^{i} C_{q q}^{j} C_{e e}^{j}>\left(C_{q e}^{i} C_{q e}^{j}\right)^{2}
$$


Subtracting the RHS of the first inequality completes the proof:

$$
\left(C_{q q}^{i} C_{e e}^{j}\right)^{2}-2 C_{q q}^{i} C_{e e}^{j} C_{q q}^{j} C_{e e}^{i}+\left(C_{q q}^{j} C_{e e}^{i}\right)^{2}=\left(C_{q q}^{i} C_{e e}^{j}-C_{q q}^{j} C_{e e}^{i}\right)^{2} \stackrel{!}{>} 0 \Rightarrow \Phi \stackrel{!}{>} 0
$$

Now I derive the sign of the other three expressions in Lemma 1 by solving Eq. A3 for the effect of firm 1's output on the output price and then using Eqs. A2 and A5:

$$
\frac{\partial p}{\partial q_{1}}=\frac{P^{\prime} \sum_{i=2}^{N} \partial x_{i} / \partial \sigma}{\sum_{i=2}^{N} \frac{\partial x_{i}}{\partial \sigma}+P^{\prime} \Phi}<0
$$

because the numerator is positive. Finally, differentiating Eq. 3 with respect to $x_{1}$ gives

$$
\left[\begin{array}{cc}
P^{\prime} \sum_{i=2}^{N} \frac{\partial q_{i}}{\partial \sigma} & P^{\prime} \sum_{i=2}^{N} \frac{\partial q_{i}}{\partial p} \\
\sum_{i=2}^{M} \frac{\partial x_{i}}{\partial \sigma} & \sum_{i=2}^{M} \frac{\partial x_{i}}{\partial p}
\end{array}\right]\left[\begin{array}{l}
\frac{\partial \sigma}{\partial x_{1}} \\
\frac{\partial p}{\partial x_{1}}
\end{array}\right]=\left[\begin{array}{l}
0 \\
-1
\end{array}\right]
$$

which can be solved for

$$
\begin{array}{r}
\frac{\partial \sigma}{\partial x_{1}}=\frac{\sum_{i=2}^{N} \partial q_{i} / \partial p}{\Phi}>0 \\
\frac{\partial p}{\partial x_{1}}=\frac{-\sum_{i=2}^{N} \partial q_{i} / \partial \sigma}{\Phi}>0
\end{array}
$$

A.2 Proof that $\bar{x}_{1}^{00}<\bar{x}_{1}^{0}$

This is equivalent to showing that $\frac{\partial p / \partial q_{1}}{\partial \sigma / \partial q_{1}} \stackrel{?}{\stackrel{?}{>}} \frac{\partial p / \partial x_{1}}{\partial \sigma / \partial x_{1}}$

Substituting Eqs. A4, A9, and A10 into this expression and simplifying yields

$$
\frac{\sum_{i=2}^{N} \partial x_{i} / \partial \sigma}{-\sum_{i=2}^{N} \partial x_{i} / \partial p} \stackrel{?}{>} \frac{-\sum_{i=2}^{N} \partial q_{i} / \partial \sigma}{\sum_{i=2}^{N} \partial q_{i} / \partial p}
$$

Multiplying both sides by the two denominators (again reversing the inequality) and bringing both terms to the left hand side gives

$$
\sum_{i=2}^{N} \frac{\partial q_{i}}{\partial \sigma} \sum_{i=2}^{N} \frac{\partial x_{i}}{\partial p}-\sum_{i=2}^{N} \frac{\partial q_{i}}{\partial p} \sum_{i=2}^{N} \frac{\partial x_{i}}{\partial \sigma}=\Phi \stackrel{!}{>} 0
$$

\section{References}

Alberola E, Chevallier J et al (2008) Price drivers and structural breaks in European carbon prices 2005-2007. Energy Policy 36:787-797

Boehringer C, Lange A (2005) Mission impossible!? On the harmonization of national allocation plans under the EU emissions trading directive. J Regul Econ 27(1):81-94

Bovenberg AL, Goulder LH (1996) Optimal environmental taxation in the presence of other taxes: generalequilibrium analyses. Am Econ Rev 86(4):985-1000

Bovenberg AL, Goulder LH (2000) Neutralizing the adverse industry impacts of $\mathrm{CO}_{2}$ abatement policies: what does it cost? RFF Discussion Papers. Washington, Resources for the Future: 48 
Brown-Kruse J, Elliot SR et al (1995) Strategic manipulation of pollution permit markets: an experimental approach. McMaster University, Department of Economics Working Papers, p 35

Bunn DW, Fezzi C (2008) A vector error correction model of the interactions among gas, electricity and carbon prices: an application to the cases of Germany and United Kingdom. In: Gulli F (ed) Markets for carbon and power pricing in Europe: theoretical issues and empirical analyses. Edward Elgar Publishing, pp 145-159

Disegni Eshel DM (2005) Optimal allocation of tradable pollution rights and market structures. J Regul Econ 28(2):205-223

Ellerman AD, Buchner B (2008) Over-allocation or abatement? A preliminary analysis of the EU ETS based on the emissions 2005 data. Environ Resour Econ 41(2):267-287

European Environment Agency (2006) Application of the emissions trading directive by EU member states. EEA Technical Report No. 2/2006

Fell H (2008) EU-ETS and Nordic electricity: a CVAR approach. Resources For the Future, Discussion Paper $08-31$

Godby R (2002) Market power in laboratory emission permit markets. Environ Resour Econ 23(3):279-318

Grubb M, Neuhoff K (2006) Allocation and competitiveness in the EU emissions trading scheme: policy overview. Clim Policy 6(1):7-30

Hahn RW (1984) Market power and transferable property rights. Q J Econ 99(4):753-765

Hart O, Tirole J (1990) Vertical integration and market foreclosure. Brookings Papers on Economic Activity (special issue), pp 205-276

Hepburn C, Grubb M et al (2006) Auctioning of EU ETS Phase II allowances: how and why? Clim Policy 6(1):137-160

Hintermann B (2009) An options pricing approach to $\mathrm{CO}_{2}$ allowances in the EU ETS. CEPE working paper \# 64. Zurich, ETHZ

Hintermann B (2010) Allowance price determinants in the EU ETS. J Environ Econ Manag (in press)

Krattenmaker TG, Salop SC (1986a) Anticompetitive exclusion: raising rivals' costs to achieve power over price. Yale Law J 96(2):209-293

Krattenmaker TG, Salop SC (1986b) Competition and cooperation in the market for exclusionary rights. Am Econ Rev 76(2):109-113

Kruger J, Pizer W (2004) The EU emissions trading directive: opportunities and potential pitfalls, Washington. Resources for the Future discussion papers: 62

Liski M, Montero J-P (2005) A note on market power in an emission permits market with banking. Environ Resour Econ 31(2):159-173

Maeda A (2003) The emergence of market power in emission rights markets: the role of initial permit distribution. J Regul Econ 24(3):293-314

Mansanet-Bataller M, Pardo A et al (2007) $\mathrm{CO}_{2}$ prices, energy and weather. Energy J 28(3):73-92

Misiolek WS, Elder HW (1989) Exclusionary manipulation of markets for pollution rights. J Environ Econ Manag 16(2):156-166

Muller RA, Mestelman S (1998) What have we learned from emissions trading experiments. Manag Decis Econ 19(4-5):225-238

Neuhoff K, Keats K et al (2006) Allocation, incentives and distortions: the impact of EU ETS emissions allowance allocations to the electricity sector. Clim Policy 6(1):73-91

Ordover JA, Saloner G et al (1990) Equilibrium vertical foreclosure. Am Econ Rev 80(1):127-142

Parry IWH (1995) Pollution taxes and revenue recycling. J Environ Econ Manag 29(3):S64-77

PEW Center on Global Climate Change (2005) The European emissions trading scheme (EU-ETS); Insights and Opportunities: 20

Reilly JM, Paltsev S (2005) An analysis of the European emission trading scheme, vol 27. Joint Program on the Science \& Policy of Global Change. Massachussetts Institute of Technology, Cambridge

Rickels W, Dusch V et al (2007) The determinants of allowance prices in the European emissions trading scheme-can we expect an efficient allowance market 2008? vol 28. Kiel Institute for the World Economy Working Paper No. 1387

Salop SC, Scheffman DT (1983) Raising rivals' costs. Am Econ Rev 73(2):267-271

Salop SC, Scheffman DT (1987) Cost-raising strategies. J Ind Econ 36(1):19-34

Sartzetakis ES (1997a) Raising rivals' cost strategies via emission permits markets. Rev Ind Organ 12(5-6):751-765

Sartzetakis ES (1997b) Tradeable emission permits regulations in the presence of imperfectly competitive product markets: welfare implications. Environ Resour Econ 9(1):65-81

Sijm J, Neuhoff K et al (2006) $\mathrm{CO}_{2}$ cost pass through and windfall profits in the power sector. Clim Policy 6(1):49-72 
Sijm JPM, Hers SJ et al (2008) The impact of the EU ETS on electricity prices. Energy Research Centre of the Netherlands (ECN), $230 \mathrm{pp}$

Sinn H-W, Schmoltzi U (1981) Eigentumsrechte, Kompensationsregeln und Marktmacht-Anmerkungen zum Coase Theorem. Jahrbuecher fur Nationalokonomie und Statistik 196(2):97-117

Smale R, Hartley M et al (2006) The impact of $\mathrm{CO}_{2}$ emissions trading on firm profits and market prices. Clim Policy 6(1):29-46

van Egteren H, Weber M (1996) Marketable permits, market power, and cheating. J Environ Econ Manag 30(2):161-173

Vollebergh HRJ, De Vries JL et al (1997) Hybrid carbon incentive mechanisms and political acceptability. Environ Resour Econ 9(1):43-63

von der Fehr N-HM (1993) Tradable emission rights and strategic interaction. Environ Resour Econ 3(2): 129-151

Westskog H (1996) Market power in a system of tradeable $\mathrm{CO}_{2}$ quotas. Energy J 17(3):85-103 